\section{Six monthly check-ups to be replaced}

Regular six-monthly dental check-ups are to be replaced with a new system where the frequency of dental check-ups will be determined by each patient's specific needs.

This is according to new guidelines launched by the National Institute for Clinical Excellence (NICE) in November. The guidelines recommend that for under $18 \mathrm{~s}$, the interval between check-ups should be between 3 and 12 months and for adults it should be between 3 and 24 months.

During the check-up a member of the dental team will be asked to go through a checklist of modifying factors with the patient that could affect the patient's dental health, such as medical and social history and dietary habits.
The recall period for the next checkup will be determined on the basis of the assessment of disease levels and risk of or from dental disease.

Six-monthly dental check-ups have been custom-

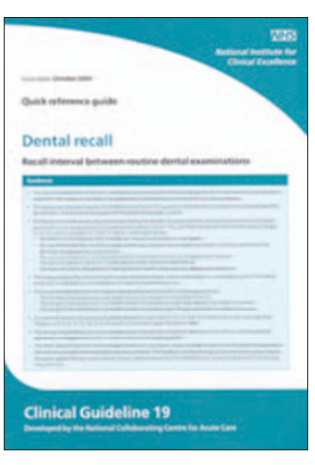
ary in the UK since the inception of the NHS, however according to Chief Dental Officer Raman Bedi, these are no longer neccessary as a result of the increasing use of fluoride toothpaste and improved oral health education.

\title{
Major change to dental technician registration
}

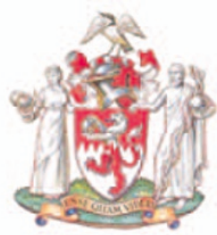

\section{General Dental Council}

The GDC has made a major change to dental technician registration and has decided that registration should be compulsory for everyone directly involved in the manufacture of dental appliances.

Under its old policy, unregistered dental laboratory workers would have been able to continue working but only GDC-registered technicians would have been able to sign off work leaving dental laboratories.

The new policy means that once the twoyear transition to PCD registration is over, all laboratory workers with hands-on involvement in the production process will either need to be GDC-registered or on a recognised training programme.

The GDC says the change in policy is in the interests of patient protection and is also based upon proposals from a collective of dental technology organisations known as the
Gateway Group, which includes the British Institute of Dental Surgical Technologists, the Central Council for Health Authority Technicians, the Clinical Dental Technician Association, the Dental Laboratories Association, the Dental Technicians Association and the Orthodontic Technicians Association.

The group made strong representations to the GDC over recent months in support of registration for all dental laboratory workers.

The criteria for registration as a dental technician are unaffected by the policy change. During the two-year transitional period, technicians will be able to register on the basis of having an approved qualification or registration on the Dental Technicians Association's voluntary register or seven years' full time experience (or the part time equivalent) in the past ten years and experience of manufacturing dental appliances in one of a number of treatment areas such as prosthodontics.

GDC Chief Executive and Registrar, Antony Townsend said, 'The new arrangements are designed to achieve higher standards of dental technology products for patients, and to encourage the dental team ethos which is at the heart of PCD registration.'

\section{Homeless} charity appeals for volunteers

As Christmas fast approaches, many of the UK's charity organisations look to the professional community to lend their support by volunteering to help in a practical way.

One such charity is Crisis, the national homelessness charity, who is appealing for dental nurses and hygienists to volunteer their skills to help homeless people this Christmas.

Last year, over 1,200 homeless and vulnerable people visited the Crisis Open Christmas shelters based in London. The shelters offer warmth, food, companionship and access to services during the festive season. The dentists, dental nurses and hygienists are a key part of the 500 professional medics who are needed to volunteer for a range of shifts and hours between 23rd and 30th December.

Dental Service Organiser, Liz Deuchars, says that the medical centre was visited by three quarters of guests last year. She adds that as many homeless people have little or no access to health services, the medical centre provides a vital lifeline.

The dental nurses and hygienists are key in treating guests who may not have visited a dentist for some time, and so the charity needs as much help as possible and urges people to get involved in order to make a difference to homeless people this Christmas.

The dental team is part of the 3,000 strong team of volunteers who give up their time over Christmas to run the shelters. The time given by all the volunteers is estimated to be worth over $\mathfrak{E} 600,000$ but more important is the warmth and understanding that guests receive from the volunteers.

One third of guests sleep rough with the rest being part of the hidden homeless population, who are trapped in hostels, B\&Bs or other temporary accommodation.

The volunteer hotline is 0207426 3872, email coc@crisis.org.uk or apply online at www.crisis.org.uk.

Liz Deuchars shares her experience of volunteering on page 20 . 
news in orief

Two new courses

\section{approved}

The GDC has recently approved two new PCD courses at the University of Portsmouth. The Certificate of Higher Education in Dental Nursing, which is a one year programme and the BSC (hons) in Dental Hygiene and Dental Therapy, which is a three year programme, started in the academic year 2004-2005.

The newly recognised qualifications will lead to GDC registration and the new dental course means that there is now a third registrable qualification route for dental nurses in addition to the National Certificate and the $\mathrm{NVQ/SVQ}$. For more information about the course please contact Carol Gough on 02392843946 or email carol.gough@port.ac.uk

Raising awareness

Smoking cessation in Scotland

NHS Health Scotland and ASH Scotland have recently announced the launch of the Smoking Cessation Guidelines for Scotland: 2004 Update.

This replaces the earlier guidelines, which were first published in 2000, and provides the most up-to-date evidence on effective smoking cessation interventions as well as guidance on service development in Scotland.

The guidelines are for health professionals to help them support smokers who want to give up. Also available is Encouraging Smokers to Stop: What you can do.

Both documents provide guidance for providers of smoking cessation services and all health professionals who have contact with smokers during the course of their work.
Key messages from the guidelines include: all health professionals should have access to information on the smoking status of their patients, should ensure that smokers have been advised to stop and that all smokers making an attempt to stop should be strongly encouraged to use specialist smoking cessation services.

The complete set of recommendations can be found in the guidelines at: www.healthscotland.com/tobacco or www.ashscotland.org.uk

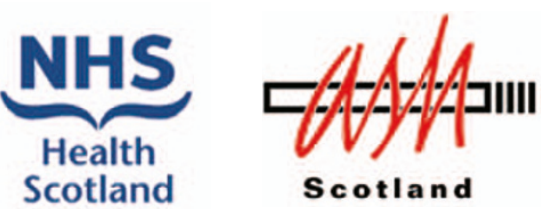

\section{BDHA conference}

The British Dental Hygienists' Association (BDHA) headed north of the border to Edinburgh for their 2004 annual conference recently.

The conference, now called the Oral Health Conference and Annual General Assembly of Members, was held on the 12th and 13th November at the Edinburgh International Conference Centre. The con- ference programme brought together a mix of speakers, a large trade exhibition, time to network with colleagues and a Scottish themed dinner.

One of the key speakers at the conference was the Deputy Chief Dental Officer of England, Barry Cockcroft who brought delegates up to date on the latest changes and in particular the Section 60 Order consultation.

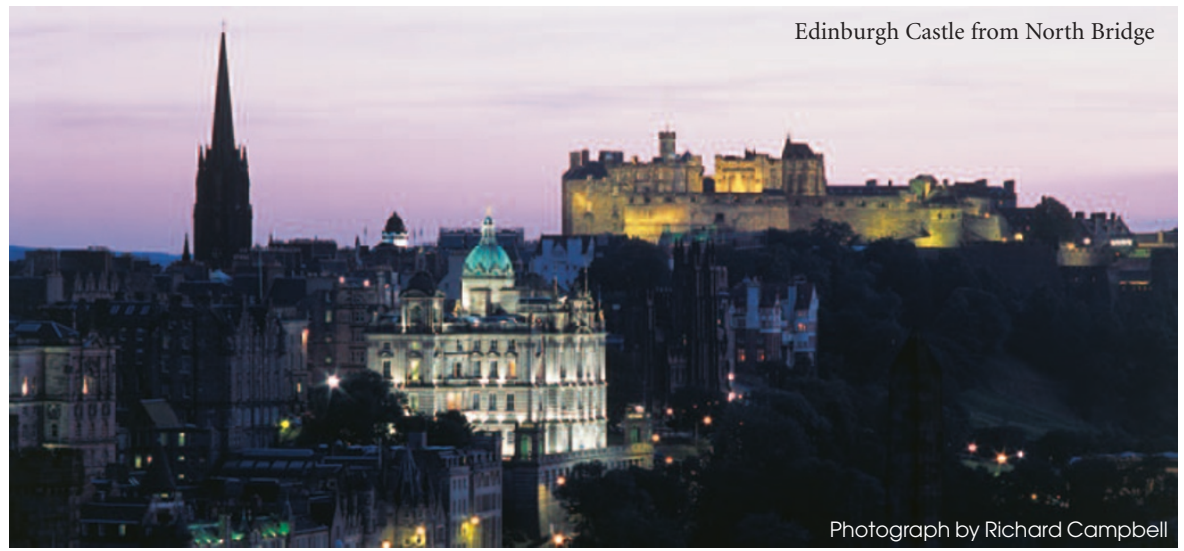




\section{Investment} in NHS dentistry

The dental team could benefit from a massive injection of cash into NHS dentistry, after the government's announcement that it is to invest an extra $£ 368$ million in NHS dentistry, recruit 1,000 more NHS dentists by October 2005 and reform the existing dental system.

In a written House of Commons statement, the Government asserts it will fund 170 extra undergraduate dental training places in England from October 2005 and revenue costs for this will reach $£ 29 m$ by $2010 / 11$ with a capital investment of $£ 80 \mathrm{~m}$ over four years to support this expansion. It claims that by $2005 / 6$, NHS dentistry will receive extra funding of over $£ 250 \mathrm{~m}$ a year and in recognition of the additional work and training dentists and their practice staff will need to prepare for changes, an extra £9 million will be provided to help dental practices prepare.

Reforms will be introduced to modernise the dentistry profession for the 21st century through a new dentists contract making it possible for them to spend more time with patients and encourage preventative care, using the skills of the entire dental team more efficiently with new roles for hygienists and dental nurses. Local Primary Care Trusts (PCTs) will use the $£ 1.6$ billion devolved budget to ensure that local expenditure on dentistry is sustained. The changes, which form the biggest reform since the service began in 1948, are designed to make dental services properly integrated with the rest of the NHS and aim to provide better access to services and an improved patient experience, according to John Reid, Secreatary of State for Health.
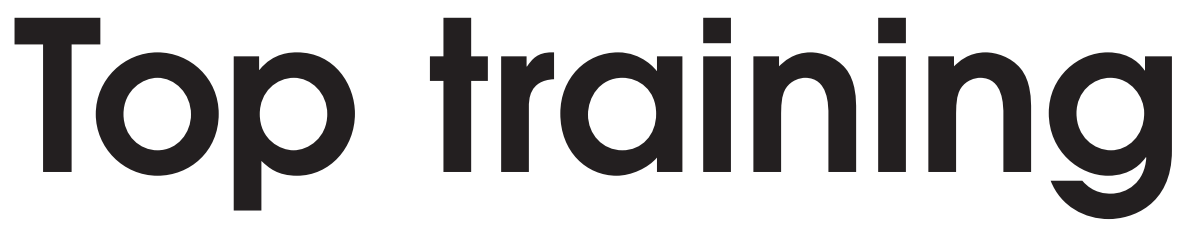

Dental professionals from across West Yorkshire attended a new training event in October when the first ever Bradford NHS Dental Day took place at the Carlisle Business Centre.

A total of 200 free places were available for dentists, dental nurses, hygienists, therapists, receptionists, practice managers and oral health educators.

The event gave the latest facts and figures on dental erosion and top prevention methods, and oral health educator, Sharon Walker, reported back on an innovative oral health promotion campaign, which was delivered within a mosque setting.

There was also a training session on safe and effective cross infection control procedures and delegates had the opportunity to visit trade stands such as Glaxosmithkline, Oral B, Dental Directory and Schulke Mayr.

Makeovers performed by Virgin Vie cosmetics were also available for just $£ 1$, along

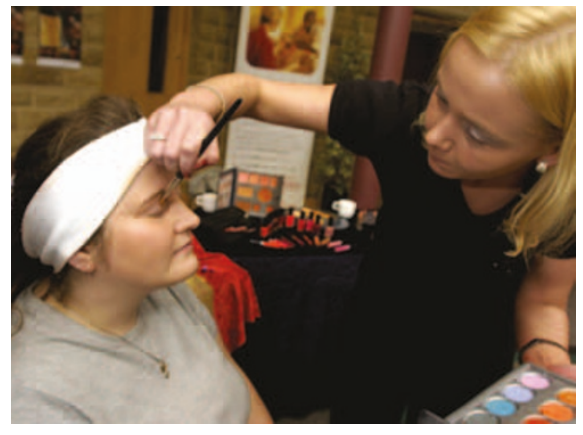

with a raffle to raise money for Dentaid, the charity that aims to improve oral health in the developing world.

'This was the first event of its kind in Bradford,' said Linda Bussey, dental nurse Care Trust (PCT), and Bradford City PCT, who ran the event. 'It gave dental staff throughout the county a chance to get together, share best practice, and receive upto-the minute training. advisor for Bradford South \& West Primary

\section{Optical Express buys Boots dental business}

The Optical Express Group has reached an agreement to acquire the Laser Eye Correction and Dentistry businesses of the Boots Group.

Optical Express is Europe's largest provider of the combination of optical services of laser eye correction, contact lenses and spectacles, and this acquisition will make it the UK's third largest dental services business. Boots announced in September that it was to exit these areas to focus on its core businesses.

Optical Express will operate the Laser Eye Correction business from the 25th October and Dentistry from the 31 st December, saving around 700 jobs.

As a result of the acquisitions, the 700 employees will transfer to Optical Express bringing the total number of employees to 2,300 for Optical Express.

David Moulsdale, Chief Executive of Optical Express and Chairman of the Royal National Institute of the Blind, RNIB (New Appeal) Scotland, commented:

'We are delighted to have agreed to acquire both businesses from Boots. Our first priority is to ensure the on-going clinical care for patients and the welfare of the employees.'

Boots operates 54 dentistry practices and nine laser eye clinics, most of which are incorporated into Boots stores. According to Boots, Optical Express has bought the equipment and the patient lists, but not the property. 